Supporting Information

\title{
Relaxation Dynamics of Enhanced Hot-Electron Flow on Perovskite-Coupled Plasmonic Silver Schottky Nanodiodes
}

Yujin Park ${ }^{1,2 \dagger}$, Jungkweon Choi ${ }^{1,2,3 \dagger}$, Mincheol Kang ${ }^{1,2}$, Hyunhwa Lee ${ }^{1,2}$, Hyotcherl Ihee $e^{1,2,3 *}$ and Jeong Young Park ${ }^{1,2 *}$

${ }^{1}$ Department of Chemistry, Korea Advanced Institute of Science and Technology (KAIST), Daejeon 34141, Republic of Korea

${ }^{2}$ Center for Nanomaterials and Chemical Reactions, Institute for Basic Science (IBS), Daejeon 34141, Republic of Korea

${ }^{3} \mathrm{KI}$ for the BioCentury, Korea Advanced Institute of Science and Technology (KAIST), Daejeon 34141, Republic of Korea

${ }^{\dagger}$ Y. P. and J. C. contributed equally to this work.

*Author to whom correspondence should be addressed. E-mail: hyotcherl.ihee@kaist.ac.kr, jeongypark@kaist.ac.kr 


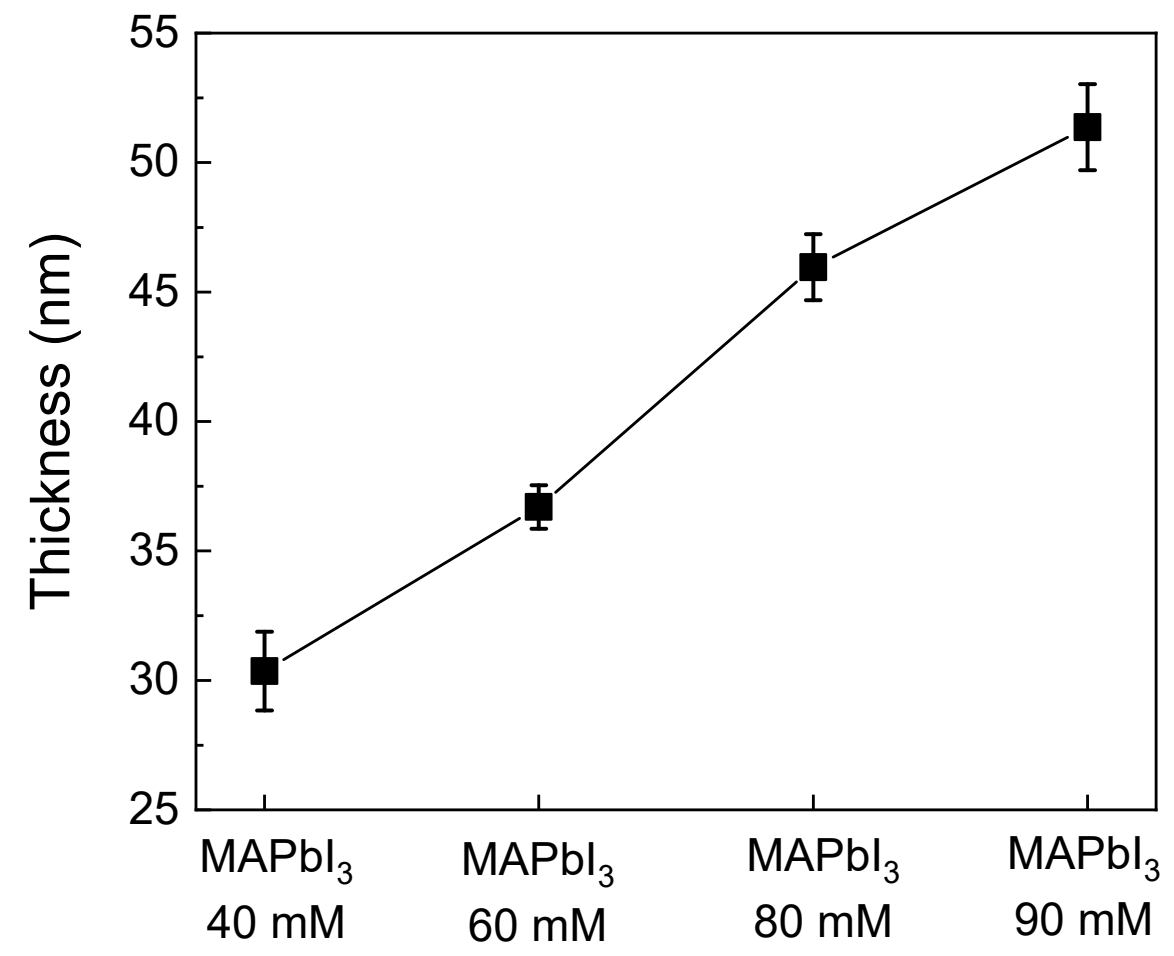

Figure S1. Thicknesses of $\mathrm{MAPbI}_{3}$ thin-film according to the deposition of different concentrations of $\mathrm{MAPbI}_{3}$ precursor ink. 

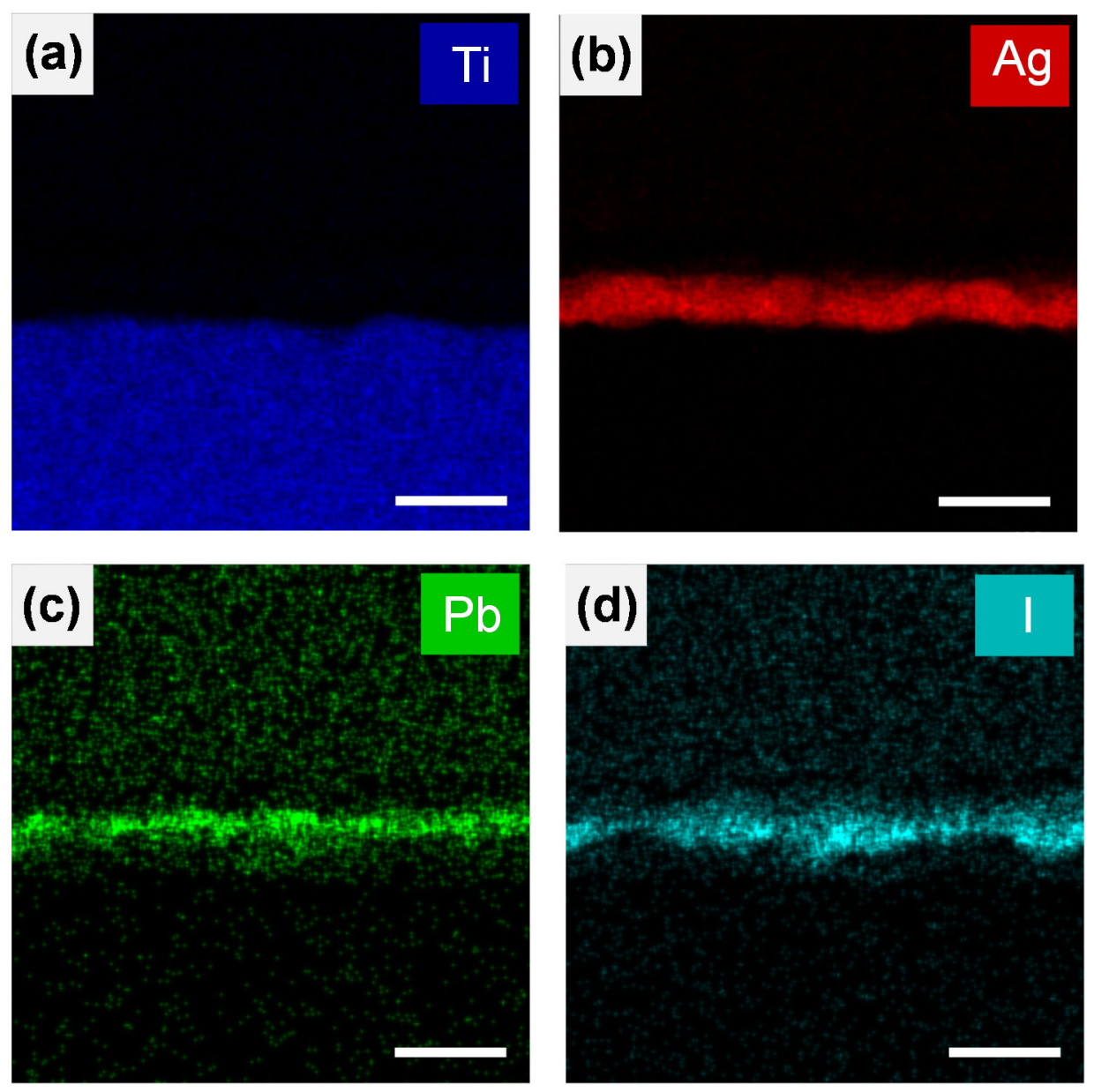

Figure S2. The STEM-EDS elemental mapping images represent (a) Ti, (b) Ag, (c) Pb, and (d) I. Scale bars are $100 \mathrm{~nm}$. 


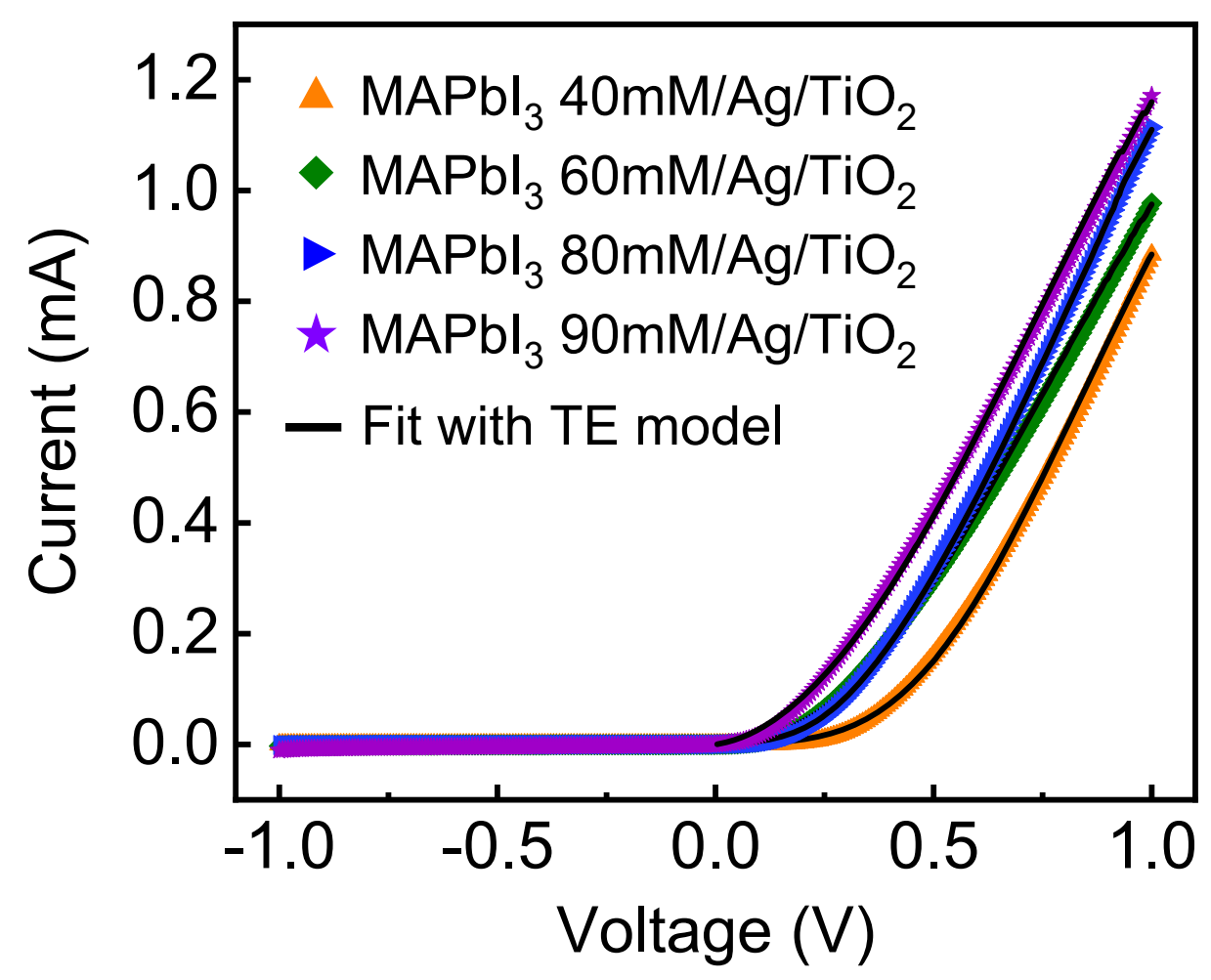

Figure S3. Current-voltage characteristics measured on the MAPbI3-modified Ag nanodiodes. The fits from the thermionic emission model are described with solid black lines.

The Schottky barrier heights can be acquired experimentally by fitting an obtained I-V curve with the thermionic emission equation, ${ }^{1}$

$$
I=A A^{* *} T^{2} \exp \left(-\frac{e E_{S B}}{k_{b} T}\right)\left[\exp \left(\frac{q\left(V-I R_{s e r}\right)}{\eta k_{b} T}-1\right)\right]
$$

where $A$ is the area of Schottky contact, $A^{* *}$ is the Richardson constant, e is the elementary charge, $E_{S B}$ is the Schottky barrier height, $k_{b}$ is the Boltzmann constant, $T$ is the temperature, $R_{\text {ser }}$ is the series resistance, and $\eta$ is the ideality factor. The acquired parameters are listed in Table S1. 


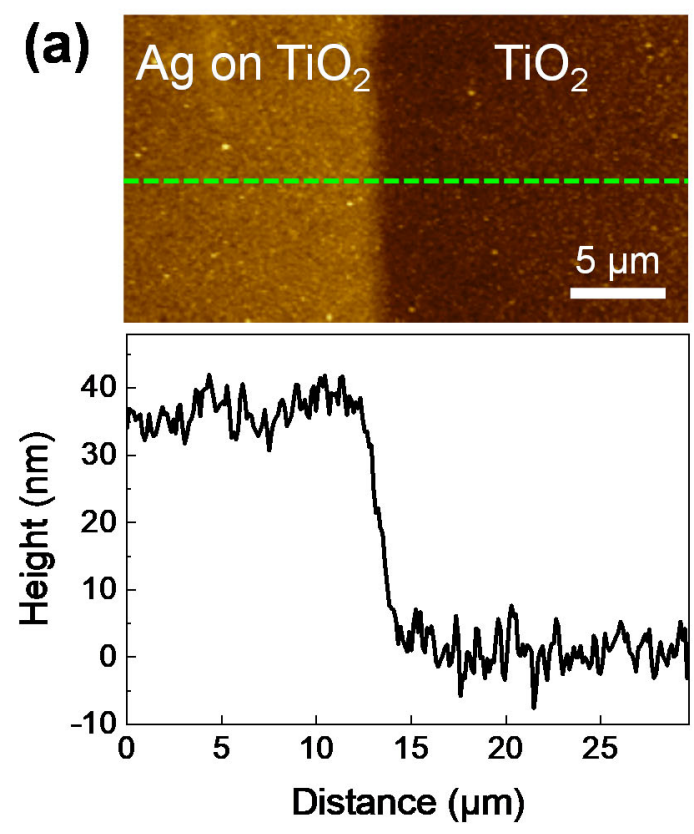

(b)

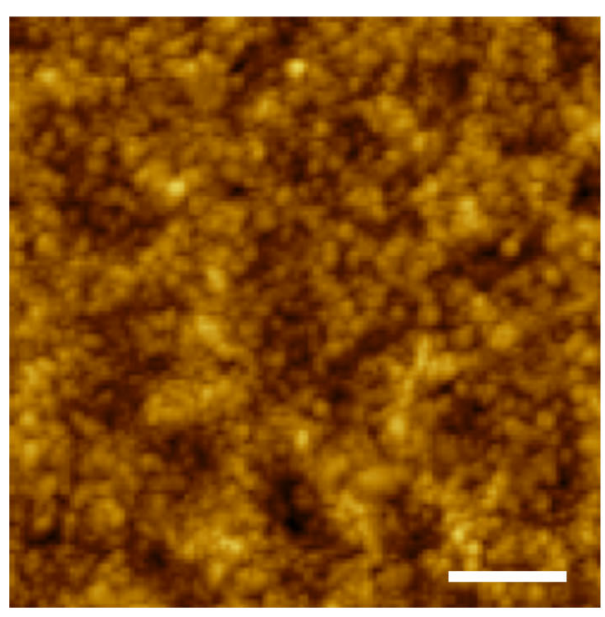

Figure S4. (a) $\mathrm{AFM}$ image of the pristine $\mathrm{Ag} / \mathrm{TiO}_{2}$ nanodiode (top) and the corresponding height profile along green dashed line (bottom). The $40 \mathrm{~nm}$ thick $\mathrm{Ag}$ film on the $\mathrm{TiO}_{2}$ layer has an RMS roughness of $5.2 \mathrm{~nm}$. (b) AFM topography image of the pristine $40 \mathrm{~nm}$ thick Ag film on the $\mathrm{TiO}_{2}$ layer. Scale bar is $500 \mathrm{~nm}$. 
(a)

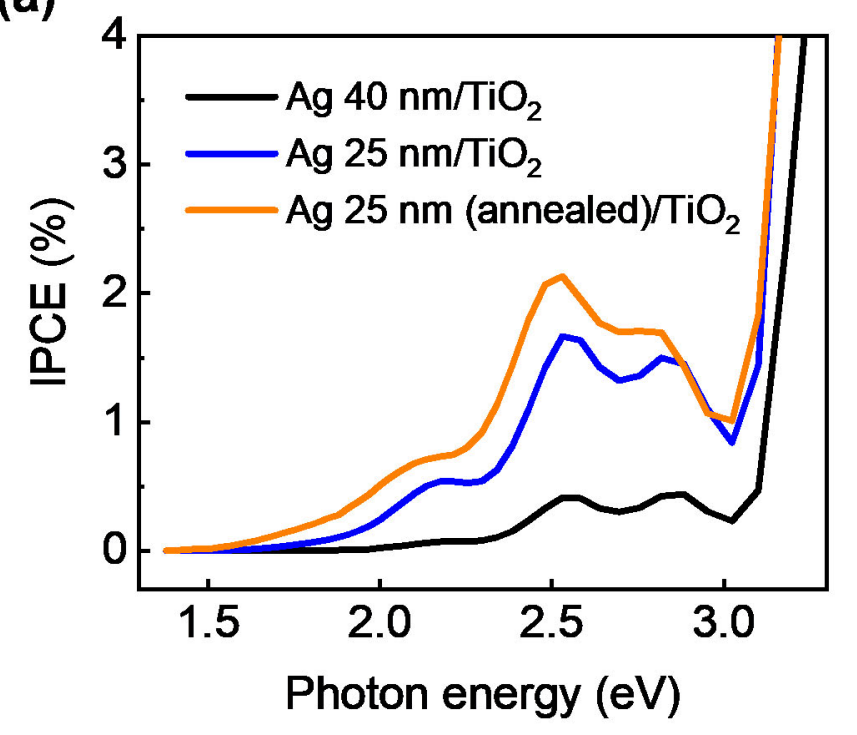

(b)

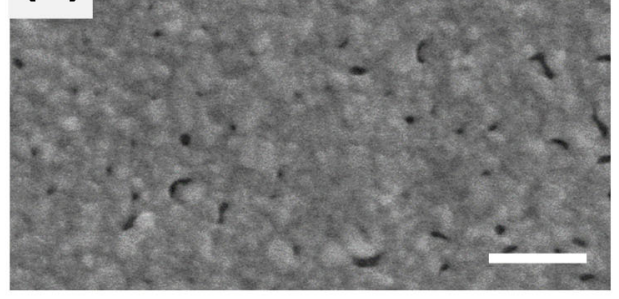

(c)

Figure S5. (a) IPCE results as a function of photon energy measured on a different Ag morphology. The surface SEM images of (b) a $25 \mathrm{~nm} \mathrm{Ag} \mathrm{film} \mathrm{and} \mathrm{(c)} \mathrm{an} \mathrm{annealed} 25 \mathrm{~nm} \mathrm{Ag}$ film are represented. Scale bars are $250 \mathrm{~nm}$. 


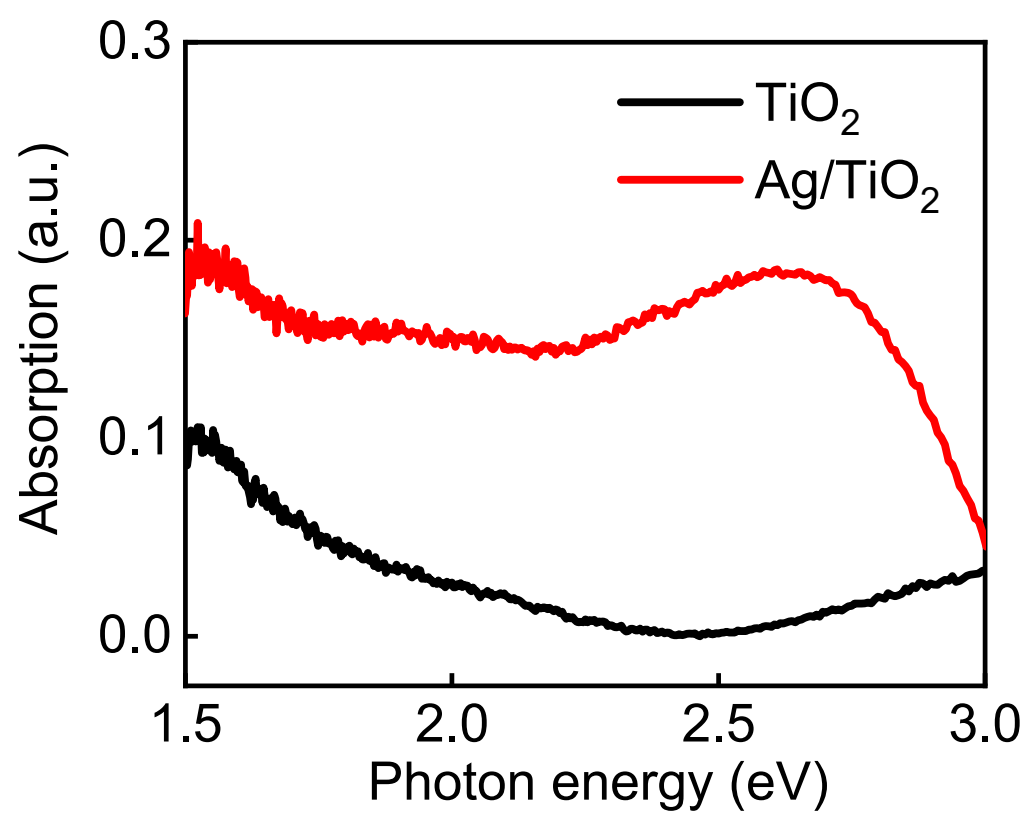

Figure S6. (a) Absorption spectrum measured on a bare $\mathrm{TiO}_{2}$ and $\mathrm{Ag} / \mathrm{TiO}_{2}$ structure. 


\begin{tabular}{lccc}
\hline & EsB $(\mathrm{eV})$ & $\mathrm{R}_{\text {ser }}(\Omega)$ & $\eta$ \\
\hline $\mathrm{MAPbI}_{3} 40 \mathrm{mM} / \mathrm{Ag} / \mathrm{TiO}_{2}$ & 0.64 & 495 & 3.1 \\
$\mathrm{MAPbI}_{3} 60 \mathrm{mM} / \mathrm{Ag} / \mathrm{TiO}_{2}$ & 0.6 & 607 & 2.86 \\
$\mathrm{MAPbI}_{3} 80 \mathrm{mM} / \mathrm{Ag} / \mathrm{TiO}_{2}$ & 0.63 & 525 & 2.42 \\
$\mathrm{MAPbI}_{3} 90 \mathrm{mM} / \mathrm{Ag} / \mathrm{TiO}_{2}$ & 0.58 & 574 & 2.65 \\
\hline
\end{tabular}

Table S1. Summary of parameters obtained by fitting measured current-voltage curves to the thermionic emission equation.

\section{Reference}

1. Sze, S. M.; Ng, K. K., Physics of Semiconductor Devices, 3rd ed.; Wiley-Interscience: Hoboken, N.J., 2007. 